\title{
Mapping of breakpoints in balanced chromosomal translocations by shallow whole-genome sequencing points to EFNA5, BAHD1 and PPP2R5E as novel candidates for genes causing human Mendelian disorders
}

\author{
Victor Murcia Pienkowski, ${ }^{1,2}$ Marzena Kucharczyk, ${ }^{3}$ Marlena Młynek, ${ }^{3}$ \\ Krzysztof Szczałuba, ${ }^{1}$ Małgorzata Rydzanicz, ${ }^{1}$ Barbara Poszewiecka, ${ }^{4}$ Agata Skórka, 3,5 \\ Maciej Sykulski, ${ }^{1,6}$ Anna Biernacka, ${ }^{1,2}$ Agnieszka Anna Koppolu, 1,2 Renata Posmyk, 7,8 \\ Anna Walczak, ${ }^{1}$ Joanna Kosińska, ${ }^{1}$ Paweł Krajewski, ${ }^{9}$ Jennifer Castaneda, ${ }^{10}$ \\ Ewa Obersztyn, ${ }^{10}$ Elżbieta Jurkiewicz, ${ }^{11}$ Robert Śmigiel, ${ }^{12}$ Anna Gambin, ${ }^{4}$ \\ Krystyna Chrzanowska, ${ }^{3}$ Małgorzata Krajewska-Walasek, ${ }^{3}$ Rafał Płoski ${ }^{1}$
}

\begin{abstract}
- Additional material is published online only. To view please visit the journal online (http://dx.doi.org/10.1136/ jmedgenet-2018-105527)
\end{abstract}

For numbered affiliations see end of article.

Correspondence to Professor Rafał Płoski Department of Medical Genetics, Medical University of Warsaw, Warsaw 02-106, Poland; rploski@wp.pl

VMP, MK and MM contributed equally.

Received 10 June 2018 Revised 21 September 2018 Accepted 22 September 2018 Published Online First 23 October 2018

Check for updates

(C) Author(s) (or their employer(s)) 2019. No commercial re-use. See rights and permissions. Published by BMJ.

To cite: Murcia Pienkowski V Kucharczyk M, Młynek M, et al. J Med Genet 2019:56:104-112.

\section{ABSTRACT}

Background Mapping the breakpoints in de novo balanced chromosomal translocations (BCT) in symptomatic individuals provides a unique opportunity to identify in an unbiased way the likely causative genetic defect and thus find novel human disease candidate genes. Our aim was to fine-map breakpoints of de novo BCTs in a case series of nine patients.

Methods Shallow whole-genome mate pair sequencing (SGMPS) together with long-range PCR and Sanger sequencing. In one case (BCT disrupting BAHD1 and $R E T)$ CDNA analysis was used to verify expression of a fusion transcript in cultured fibroblasts.

Results In all nine probands 11 disrupted genes were found, that is, EFNA5, EBF3, LARGE, PPP2R5E, TXNDC5, ZNF423, NIPBL, BAHD1, RET, TRPS1 and SLC4A10. Five subjects had translocations that disrupted genes with so far unknown (EFNA5, BAHD1, PPP2R5E, TXNDC5) or poorly delineated impact on the phenotype (SLC4A10, two previous reports of $\mathrm{BCT}$ disrupting the gene). The four genes with no previous disease associations (EFNA5, BAHD1, PPP2R5E, TXND(5), when compared with all human genes by a bootstrap test, had significantly higher $\mathrm{pLI}(\mathrm{p}<0.017)$ and DOMINO $(p<0.02)$ scores indicating enrichment in genes likely to be intolerant to single copy damage. Inspection of individual pLI and DOMINO scores, and local topologically associating domain structure suggested that EFNA5, BAHD1 and PPP2R5E were particularly good candidates for novel disease loci. The pathomechanism for BAHD1 may involve deregulation of expression due to fusion with RET promoter

Conclusion SGMPS in symptomatic carriers of BCTs is a powerful approach to delineate novel human genedisease associations.

\section{INTRODUCTION}

Balanced chromosomal translocations (BCT) cause exchange of genetic material between non-homologous chromosomes without any change in the amount of DNA. ${ }^{1}$ De novo BCTs have a frequency of 1 per 2000 live births. ${ }^{2}$ Most individuals with BCTs are healthy, nonetheless in up to $26.8 \%$ of cases, BCTs are associated with clinical pathology. ${ }^{3}$ Symptomatic BCTs provide a unique opportunity to identify the causative genetic mechanism as it is likely that such a mechanism is directly related to genome damage inflicted by the breakpoint(s).

BCT may cause a disease by direct disruption of a gene through intragenic break that is pathogenic through haploinsufficiency. ${ }^{4}$ It is also possible that BCT creates a chimeric gene causing an expression of a novel protein or a novel promoter-gene combination. This mechanism occurring in somatic cells can cause cancer but there are also reports of similar germline events being responsible for mental retardation or psychiatric diseases. ${ }^{5-8}$ Finally, the BCT breakpoint(s) may disrupt topologically associating domain (TAD) structure affecting regulatory elements and altering expression of genes that have not been directly damaged ,i.e. long-range position effect (LRPE). ${ }^{9-11}$

Historically, breakpoints in BCTs were mapped using karyotyping which was laborious and had limited resolution. ${ }^{12} 13$ Next-generation sequencing (NGS) allowing whole-genome sequencing, in particular in the format of shallow genome mate pair sequencing (SGMPS), has considerably simplified identification of BCT breakpoints. ${ }^{114}$

In this study we present the results of de novo BCT mapping in a case series of nine symptomatic probands using SGMPS with a focus on cases where findings point to novel human disease candidate genes.

\section{Patients}

Written informed consent for all the genetic studies performed on the patients and their parents was obtained from the patients' legal guardians. 
We studied nine symptomatic cases in whom de novo BCTs were found by standard karyotyping. The clinical inclusion criteria consisted of developmental delay, neurological dysfunction, congenital anomalies and/or dysmorphic features raising a suspicion of a known or novel genetically determined disease/ syndrome. In all cases, translocations were confirmed as balanced by array comparative genomic hybridisation (aCGH). Furthermore, no de novo CNVs were found in any of the probands. The detailed clinical characteristic of five probands with breakpoint(s) in genes with unknown/poorly delineated disease phenotype is given below and summarised in table 1 . Description of the remaining patients in whom the phenotype was considered as (likely/possibly) explained by the observed breakpoint(s) is shown in table 2 .

\section{Proband 1}

The boy was the first child of healthy, non-consanguineous parents. The pregnancy was uneventful except for maternal hypothyroidism, treated effectively with thyroid hormone replacement. Birth weight at 39th week was $2160 \mathrm{~g}(<0.4$ th centile), length $48 \mathrm{~cm}$ (10th centile) and Apgar scores were 10 both at 1 and $5 \mathrm{~min}$. At birth he was hypotonic, had bilateral cloudy cornea and several dysmorphic features. At 12 months he had square face; high forehead; bilateral epicanthic folds; sparse eyebrows; short and upturned nose; long and flat philtrum; narrow upper lip; micrognathia; small, dysplastic, posteriorly rotated and low-set ears; hypoplastic nipples; short distal phalanges of fingers; bilateral single palmar crease; syndactyly of second and third toes; and mild sandal gap.

Echocardiogram showed supravalvular pulmonary stenosis and atrial septal defect. Renal and cranial ultrasound was normal but abdominal ultrasound examination showed a portosystemic venous shunt. Consequent ultrasound and Doppler study of the abdomen revealed drainage of the left branch of the portal vein into the left hepatic vein and the boy was diagnosed with Abernethy malformation type II. The aberrant vessel was $3.3 \mathrm{~mm}$ in diameter. At 6 months the shunt was successfully occluded by embolisation with Amplatzer vascular plug.

The ophthalmologic evaluation revealed bilateral cloudy cornea caused by persistent corneal fetal vascularisation, but apparently without retinal involvement. Audiometric testing (auditory brainstem response (ABR), tympanometry and distortion product otoacoustic emissions (DPOAE)) performed at 2 months was normal.

\section{Proband 2}

The boy was born at 40th week with the following parameters: weight $3800 \mathrm{~g}$ (75th centile), length $59 \mathrm{~cm}$ (>90th centile), head circumference $35 \mathrm{~cm}$ (50th-75th centiles). The pregnancy was uncomplicated. Motor development was delayed: he sat unsupported at 6 months, walked unassisted at 18 months and said his first words at 2 years. At 21 years he was referred to genetic counselling unit due to moderate intellectual disability, hyperactivity features, coordination disorder and strange behavioural pattern consisting of sniffing. Body weight was $94 \mathrm{~kg}$, height $194 \mathrm{~cm}$ ( $>97$ th centile) and occipitofrontal circumference (OFC) $57 \mathrm{~cm}$ (50th centile). He attends special school and has significant speech delay. His dysmorphism includes distal hand camptodactyly and unilateral transverse palmar crease. CT of the brain was normal.

\section{Proband 3}

The girl was born from the first pregnancy of healthy and non-consanguineous parents at 40th week with birth weight $2950 \mathrm{~g}$ (5th-10th centiles), length $52 \mathrm{~cm}$ (90th centile) and Apgar score of 7 (OFC was not measured). During the first week septic ileus developed and gastrostomy was performed followed by colectomy at 9 months due to Hirschsprung disease (Mendelian Inheritance in Man (MIM): 142623). Since 10 months of age the girl experienced recurrent urinary tract infections and, eventually, complement proteins deficit was diagnosed and appropriate treatment started. Her physical and psychomotor development was near normal up to 13 years when progressive intellectual deterioration occurred. Her IQ declined from 96 to 46 by 20 years. There were: learning difficulties, anxiety, depression, catatonic stupor, loss of previously gained abilities, incomprehensible speech and social withdrawal. A diagnosis of schizophrenia (paranoid type) was made. Electroencephalography (EEG) tracings showed generalised discharges of spikes as well as polyspike slow-wave pattern.

At 21 years her physical parameters were: weight $60 \mathrm{~kg}$ (75th centile), height $160 \mathrm{~cm}$ (25th centile) and OFC $55 \mathrm{~cm}$ (50th centile). She has large, soft and narrow hands with mild shortening of the metacarpals and long tapering fingers. Head MRIs at 11, 14 and 17 years showed irregular angiogenic lesions in the white matter of the paraventricular right frontoparietal region, the neighbourhood of the collateral trigone of the left lateral ventricle and frontal lobe. In addition, the lateral ventricles were slightly widened.

\section{Proband 4}

The girl was born to healthy parents at 40th week by caesarean section (fetal heart rate disturbances) with Apgar score of 10, weight $2830 \mathrm{~g}$ (5th-10th centiles), height $54 \mathrm{~cm}$ (90th centile) and head circumference $33 \mathrm{~cm}$ (5th centile). The pregnancy was complicated by oligohydramnios and maternal pre-eclampsia. In neonatal period, there was hypertonia which subsided after the 1 year of age. Motor development was slightly delayed: she sat unsupported at 8-9 months, walked unassisted at 15 months and said her first words at 1 year. Sleep disturbances were noted in infancy. The disproportion between body weight and height remained. At preschool age she experienced recurrent infections (bronchitis, pneumonia and strep throat), abdominal pains, aphthous stomatitis and bloating. She had unexplained bedwetting episodes. Ophthalmological examination revealed hyperopia and astigmatism, pigment dystrophy in the eye fundi and visual agnosia, and spatial apraxia.

At 12 years she was referred to a geneticist due to global developmental delay and low body weight of $35 \mathrm{~kg}$ ( $3 \mathrm{rd}$ centile) with height of $148 \mathrm{~cm}$ (3rd-10th centiles) and OFC $53 \mathrm{~cm}$ (25th centile). She attends a special school for children with impaired vision but have learning difficulties. Overall her cognitive development is good; vocabulary, knowledge and reasoning are adequate for age. Her dysmorphism includes subtle hirsutism, low back hairline, coarse facial features and rounded nasal tip. Brain MRI, EEG, urine amino and organic acids, plasma amino acids, and renal and abdominal ultrasound were normal. On aCGH, paternally inherited duplication at $3 \mathrm{p} 22$ was found. At 16 years the girl has mild intellectual delay and personality disorder, and suffers from self-mutilation.

\section{Proband 5}

The girl was born to healthy parents at 41st week from the first pregnancy with Apgar score of $9 / 10$ in $1 / 5 \mathrm{~min}$, weight $3620 \mathrm{~g}$ 


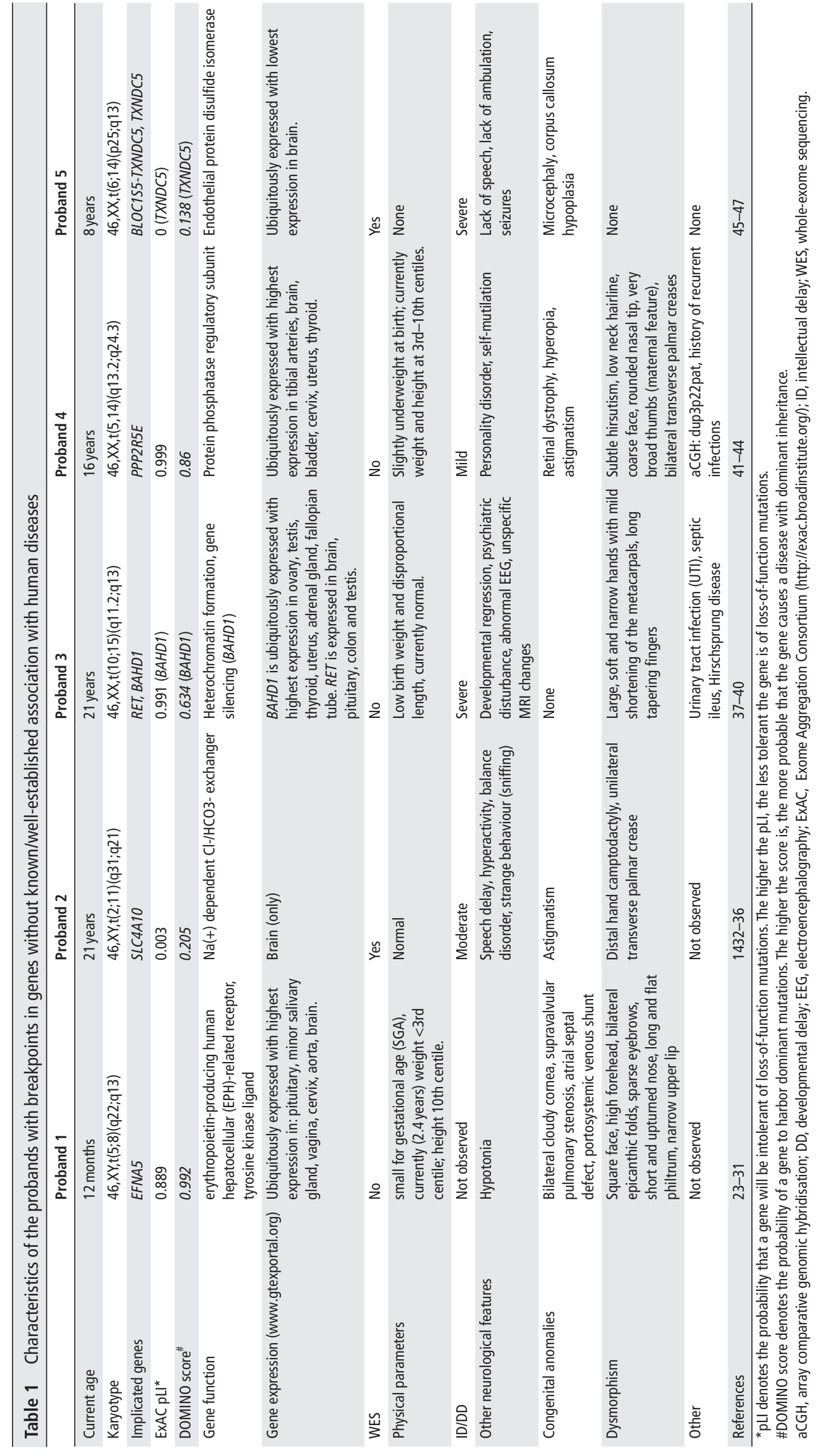


Table 2 Characteristics of the probands with breakpoints in genes with known impact on phenotype

\begin{tabular}{|c|c|c|c|c|}
\hline & Proband 6 & Proband 7 & Proband 8 & Proband 9 \\
\hline Current age & 8 years & 5 years & 10 months & 34 years \\
\hline Karyotype & $46, X Y, t(10 ; 22)(q 26.1 ; q 12.3)$ & $46, \mathrm{XX}, \mathrm{t}(1 ; 16)(\mathrm{p} 13.2 ; \mathrm{q} 13)$ & $46, X Y, t(5 ; 8)(p 13 ; q 21.2)$ & $46, X Y, t(2 ; 8)(q 31 ; q 24.1)$ \\
\hline Implicated gene(s) & $E B F 3$, LARGE & ZNF423 & NIPBL & TRPS1 \\
\hline MIM number* & 607407 (EBF3), 603590 (LARGE) & 604557 & 608667 & 604386 \\
\hline WES & No & No & No & No \\
\hline Physical parameters & Low birth weight, currently normal & $\begin{array}{l}\text { Normal at birth, FTT, currently low weight } \\
\text { and short for age }\end{array}$ & $\begin{array}{l}\text { Prenatal growth retardation, low } \\
\text { birth weight }(1840 \mathrm{~g}) \text {. Recently failure } \\
\text { to thrive, low weight, low-pitched, } \\
\text { growling cry in infancy, sensorineural } \\
\text { hearing loss. }\end{array}$ & Normal \\
\hline
\end{tabular}

\begin{tabular}{|c|c|c|c|c|}
\hline ID/DD & Moderate & Moderate & Moderate & Not observed \\
\hline $\begin{array}{l}\text { Other neurological } \\
\text { features }\end{array}$ & $\begin{array}{l}\text { Neonatal hypotonia and later } \\
\text { hypertonicity, speech delay, ADHD, fits of } \\
\text { anger, abnormal EEG }\end{array}$ & $\begin{array}{l}\text { Hypotonia, sound hypersensitivity, } \\
\text { hyperactivity, speech delay, autistic } \\
\text { features }\end{array}$ & $\begin{array}{l}\text { Hypertonia in neonatal period, } \\
\text { psychomotor developmental delay }\end{array}$ & None \\
\hline Congenital anomalies & $\begin{array}{l}\text { Total anomalous pulmonary venous } \\
\text { return (TAPVR) }\end{array}$ & $\begin{array}{l}\text { Hypoplastic thumbs, unilateral thumb } \\
\text { symphalangism, strabismus and } \\
\text { hyperopia, brain MRI (at } 5 \text { years): slightly } \\
\text { dilated frontal horns and bodies of the } \\
\text { lateral ventricles, small anterior pituitary } \\
\text { lobe }\end{array}$ & $\begin{array}{l}\text { Four hypoplastic fingers and a single } \\
\text { transverse palmar crease on the left } \\
\text { hand; bilateral cryptorchidism; atrial } \\
\text { septal heart defect (ASD), gastro- } \\
\text { oesophageal reflux, hirsutism }\end{array}$ & None \\
\hline Dysmorphism & $\begin{array}{l}\text { Tall forehead, straight eyebrows, narrow } \\
\text { palpebral fissures, unilateral epicanthic } \\
\text { fold. } \\
\text { Anteverted short nostrils, thin lips with } \\
\text { downturned corners of the mouth, } \\
\text { short and broad chin, short hands, pes } \\
\text { planovalgus, square toes with sandal } \\
\text { gap. }\end{array}$ & $\begin{array}{l}\text { Short palpebral fissures, telecanthus, flat } \\
\text { and wide nose, hypoplastic nasal alae, } \\
\text { low-set ears, micrognathia, high palate, } \\
\text { hypertelorism. }\end{array}$ & $\begin{array}{l}\text { Typical CdLS phenotype: microcephaly, } \\
\text { synophrys, deep-set eyes, long } \\
\text { eyelashes, long and prominent } \\
\text { philtrum, microretrognathia }\end{array}$ & $\begin{array}{l}\text { Typical frontal bulbous pear-shaped } \\
\text { nose, broad philtrum, thin upper } \\
\text { lip, large ears, hand and foot } \\
\text { brachydactyly, broad thumbs and big } \\
\text { toes, funnel chest }\end{array}$ \\
\hline Diagnosis & $\begin{array}{l}\text { EBF3 delayed development syndrome } \\
\text { (MIM: } 617330 \text { ) }\end{array}$ & $\begin{array}{l}\text { Atypical disease from the ZNF423 } \\
\text { spectrum (MIM: 614844)? }\end{array}$ & $\begin{array}{l}\text { Cornelia de Lange syndrome (MIM: } \\
\text { 122470) }\end{array}$ & $\begin{array}{l}\text { Trichorhinophalangeal syndrome (MIM: } \\
\text { 190350) }\end{array}$ \\
\hline Other & Urinary bladder malfunction, coprophilia & None & None & None \\
\hline
\end{tabular}

*Online Mendelian Inheritance in Man (OMIM, https://www.omim.org/).

$A D H D$, attention-deficit/hyperactivity disorder; DD, developmental delay; EEG, electroencephalography; FTT, failure to thrive; ID, intellectual delay; WES, whole-exome sequencing.

(50th centile), height $57 \mathrm{~cm}$ ( $>97$ th centile) and head circumference $32 \mathrm{~cm}$ ( $3 \mathrm{rd}$ centile). The pregnancy was uncomplicated apart from smaller OFC in fetal ultrasonography examinations. In neonatal period, microcephaly and hypotonia were observed which subsided after the first year. No congenital defects were noted after birth. Epileptic seizures refractory to treatment occurred from the 12th month. Brain MRI at 9 months showed hypoplasia of frontal part of corpus callosum. Control MRI at 7 years was normal. She has never achieved sitting, walking or speaking; sleep disturbances and excessive salivation were noted in infancy and throughout childhood. At the last follow-up, at 8 years, her weight was $16 \mathrm{~kg}$ ( $<3 \mathrm{rd}$ centile), length $138 \mathrm{~cm}$ (75 th90 th centiles) and head circumference $48 \mathrm{~cm}$ ( $<3 \mathrm{rd}$ centile); she was without eye contact or verbal communication.

\section{METHODS}

\section{Sample preparation}

DNA of nine probands and their parents was isolated with the salting out method. Prior to SGMPS, karyotype analysis and aCGH were performed. aCGH was performed using commercially available arrays (CytoSure, Constitutional v3 $(8 \times 60 \mathrm{k})$, Oxford Gene Technology, Oxfordshire, UK, for all patients except probands 2 and 3 for whom Agilent Technologies SurePrint G3 CGH+SNP $(4 \times 180 \mathrm{~K})$ was used). CytoGenomics V.4.0.3.12 software was used for genomic copy-number analysis.

\section{Mate pair library preparation and sequencing}

Up to $1 \mu \mathrm{g}$ of high-quality genomic DNA was used for library generation with the Mate Pair Library Preparation Kit (Illumina, San Diego, CA, USA) according to the manufacturer's instructions. The insert size length obtained varied from 2 to $4 \mathrm{~kb}$. Mate-pair library was paired-end sequenced $(2 \times 100 \mathrm{bp})$ on Illumina HiSeq1500. Raw sequence reads were converted to the fastq format using the Illumina bcl2fastq program. After the quality control step, including adapter trimming and low-quality reads removal, reads were mapped to the reference genome (hg19) using bowtie2. ${ }^{15}$ Each read from read pair was mapped independently and only unique mapped reads were used for further analysis. The .bam file was used for narrowing down the region where the translocations were located. A custommade package for the programming language ' $R$ ' was applied for detection of discordant reads (paired reads where one read of the pair maps to one chromosome and the second read maps to another chromosome). Only clusters of 15 or more similar discordant reads between chromosomes with the translocation were further analysed. For visual verification of the results Integrative Genomics Viewer (IGV) was used. ${ }^{16}$

\section{Whole-exome sequencing}

In two probands whole-exome sequencing (WES) was performed, as SGMPS did not fully explain the phenotype of the patient. WES library was paired-end sequenced $(2 \times 100 \mathrm{bp})$ on Illumina HiSeq 1500, with the enrichment performed with SureSelect Human All Exon v5 kit (Agilent, Santa Clara, CA, USA) according to the manufacturer's instructions. Bioinformatic analysis was conducted as described previously. ${ }^{17}$

\section{Validation of the SGMPS results}

Validation of the results of SGMPS was performed using Sanger sequencing. The PCR primers were designed using Primer3Plus 
(http://www.bioinformatics.nl/cgi-bin/primer3 plus/primer3 plus. cgi). Primer sequences and conditions for the PCR reaction are available on request. Verification of the specificity of the primers was performed using Primer Blast programme (https:// www.ncbi.nlm.nih.gov/tools/primer-blast/). Samples for Sanger sequencing were prepared with BigDye Terminator v3.1 Cycle Sequencing Kit (Applied Biosystems, Foster City, USA) and analysed on 3500xL Genetic Analyzer (Applied Biosystems). Results were assessed with Variant Reporter V.1.1 software. Verification of the de novo status of the BCTs was confirmed using PCR reaction specific for the translocation. Parenthood was verified using AmpFLSTR NGM kit (Thermo Fisher Scientific) according to the manufacturer's instructions. The status of single nucleotide variants was verified by deep amplicon sequencing in both the parents and the probands. PCR amplification and design of the primers were done as described above. The library was prepared with Nextera XT (NXT) DNA Preparation Kit (Illumina), and paired-end sequenced $(2 \times 100 \mathrm{bp})$ on Illumina HiSeq1500. Analysis of NXT results was conducted manually with IGV. Detected translocations (figure 1) were called using a newly proposed genomic nomenclature for structural chromosomal rearrangements detected by NGS. ${ }^{18}$ The likelihood that a gene was sensitive to mutation/deregulation of a single allele was estimated using pLI score from Exome Aggregation Consortium $(\mathrm{ExAC})^{19}$ and the recently proposed DOMINO score. ${ }^{20}$

\section{Fibroblasts culture and RNA analysis}

Skin fibroblasts from proband 3 were cultivated in cell culture flasks containing Dulbecco's Modified Eagle's Medium and Nutrient Mixture F-12, supplemented with 10\% fetal bovine serum and penicillin/streptomycin $100 \mathrm{U} / \mathrm{mL}$ (GIBCO, BRL, Grand Island, NY, USA). The culture was sustained at $37^{\circ} \mathrm{C} / 5 \%$ $\mathrm{CO}_{2}$ until 80\%-90\% confluency. Isolation of the RNA from fibroblasts was conducted with TRIzol Reagent (Life Technologies, Carlsbad, California, USA) in accordance with the manufacturer's instructions. Reverse transcription was carried out with High-Capacity cDNA Reverse Transcription Kit (Life Technologies). The PCR reaction and Sanger sequencing of the amplified cDNA were performed as described in 'Validation of the SGMPS results'.

\section{TAD analysis}

TADs were detected with Insulation Score method ${ }^{21}$ using Hi-C data from human GM12878 B-lymphoblastoid cells. ${ }^{22}$ Plots showing genomic regions flanking the translocation breakpoints were generated by TADeus web service (http://bioputer.mimuw. edu.pl/tadeus, details in online supplementary methods).

\section{Statistical analysis}

In order to compare the distribution of pLI and DOMINO scores for genes which were directly disrupted in probands with potentially novel diseases (EFNA5, BAHD1, PPP2R5E, TXNDC5) versus all other human genes we performed a bootstrap test including 100000 replicates on medians of the respective scores' values.

\section{RESULTS}

In all cases, BCT breakpoints were successfully mapped (online supplementary figure 1). Five out of nine analysed probands had breakpoint(s) in genes without a known disease phenotype. These patients are presented in detail below and in table 1. Additionally for these probands, TADs structure in the breakpoint region and characteristics of associated genes are presented in online supplementary file 1 . The patients with breakpoints in genes with known disease associations which (in all cases) were consistent with clinically observed phenotype are presented in table 2 .

\section{Proband 1}

SGMPS, based on 21 discordant reads and two split reads, defined the translocation as $46, \mathrm{XY}, \mathrm{t}(5 ; 8)(\mathrm{q} 21.3: \mathrm{q} 11.21)$ with exact location for chromosome $\operatorname{der}(5)$ : 46,XX,t $(5 ; 8)$ (q21.3:q11.21) dn.seq[GRCh37/hg19] $\mathrm{t}(5 ; 8) \quad(5 \mathrm{pter} \rightarrow 5 \mathrm{q} 21.3$ $(106,748,346):: 8 \mathrm{q} 11.21(55,326,842) \rightarrow 8 \mathrm{qter})$; and for chromosome der(8): 46,XX,t(5;8) (q21.3:q11.21) dn.seq[GRCh37/ hg19] $\mathrm{t}(5 ; 8) \quad(8 \mathrm{pter} \rightarrow 8 \mathrm{q} 11.21 \quad(55,326,759):: 5 \mathrm{q} 21.3$ $(106,748,356) \rightarrow 5$ qter $)$. The breakpoint in chr5 is located in the third intron out of five introns of the EFNA5 (MIM: 601535) gene, while the breakpoint in chr8 is located in non-coding DNA.

\section{Proband 2}

SGMPS, based on 20 discordant reads and one split read, defined the translocation as $46, \mathrm{XY}, \mathrm{t}(2 ; 11)(\mathrm{q} 24.2 ; \mathrm{q} 21)$ with exact location for chromosome der $(2)$ :

46,XX,t $(2 ; 11)(\mathrm{q} 24.2: \mathrm{q} 21) \mathrm{dn} . \mathrm{seq}[\mathrm{GRCh} 37 / \mathrm{hg} 19] \mathrm{t}(2 ; 11)$ $(2$ pter $\rightarrow 2 q 24.2 \quad(162,667,703):: 11 q 21(92,976,817) \rightarrow 11$ qter); and for chromosome $\operatorname{der}(11) 46, \mathrm{XX}, \mathrm{t}(2 ; 11)(\mathrm{q} 24.2: \mathrm{q} 21)$ dn.seq[GRCh37/hg19]t $(2 ; 11)(11$ pter $\rightarrow 11$ q21 $(92,976,811)$ $:: 8 \mathrm{q} 24.2(162,667,701) \rightarrow 2 \mathrm{qter})$. The breakpoint in chr2 is located in the fourth intron out of 26 introns of the SLC4A10 (MIM: 605556) gene, while the breakpoint in chr11 is located in non-coding DNA. Based on the results from WES, four variants have been chosen for verification, but were excluded as disease candidates after family study (online supplementary table 1).

\section{Proband 3}

SGMPS, based on 15 discordant reads and one split read, defined the translocation as $46, \mathrm{XX}, \mathrm{t}(10 ; 15)(\mathrm{q} 11.21 ; \mathrm{q} 15.1)$ with exact location for chromosome $\operatorname{der}(10)$ :

46, XX, t $(10 ; 15)(\mathrm{q} 11.21: \mathrm{q} 15.1) \mathrm{dn} . \mathrm{seq}[\mathrm{GRCh} 37 / \mathrm{hg} 19]$ $\mathrm{t}(10 ; 15)(10 \mathrm{pter} \rightarrow 10 \mathrm{q} 11.21 \quad(43,594,152):: 15 \mathrm{q} 15.1$ $(40,735,863) \rightarrow 15$ qter $)$; and for chromosome $\operatorname{der}(15) 46$, XX,t(10;15)(q11.21:q15.1)dn.seq[GRCh37/hg19]t $(10 ; 15)$ $(15 \mathrm{pter} \rightarrow 15 \mathrm{q} 15.1 \quad(40,735,866):: 10 \mathrm{q} 11.21(43,598,782) \rightarrow 10$ qter). The breakpoint in chr10 is located in the first intron out of 20 introns of the RET (MIM: 164761) gene, while the breakpoint in chr15 is in the second intron out of seven introns in the BAHD1 (MIM: 613880) gene. In chromosome der(15), an insertion of around $500 \mathrm{bp}$, consisting of an intronic inverted fragment of RET gene, has been found. Sanger sequencing of the mRNA (cDNA) from fibroblasts identified expression of the fusion gene consisting of the promoter from RET gene and exons from BAHD1 (figure 1D).

\section{Proband 4}

SGMPS, based on 27 discordant reads and one split read, defined the translocation as $46, \mathrm{XX}, \mathrm{t}(5,14)(\mathrm{q} 11.2 ; \mathrm{q} 23.2)$ with exact location for chromosome $\operatorname{der}(5)$ : 46,XX,t $(5,14)(\mathrm{q} 11.2 ; \mathrm{q} 23.2) \mathrm{dn}$. seq[GRCh37/hg19]t (5;14)(5pter $\rightarrow 5$ q11.2 (54,203,477)::14q23.2 $(63,908,907) \rightarrow 14$ qter $)$; and for chromosome $\operatorname{der}(14) 46, \mathrm{XX}, \mathrm{t}(5$, 14)(q11.2;q23.2)dn.seq[GRCh37/hg19]t $(5 ; 14)(14$ pter $\rightarrow 14 \mathrm{q} 23.2$ $(63,908,904):: 5 q 11.2(54,203,482) \rightarrow 5$ qter $)$. The breakpoint in chr5 is in non-coding DNA, while the breakpoint in chr14 is in the third intron out of 14 introns in the PPP2R5E (MIM: 601647) gene. 


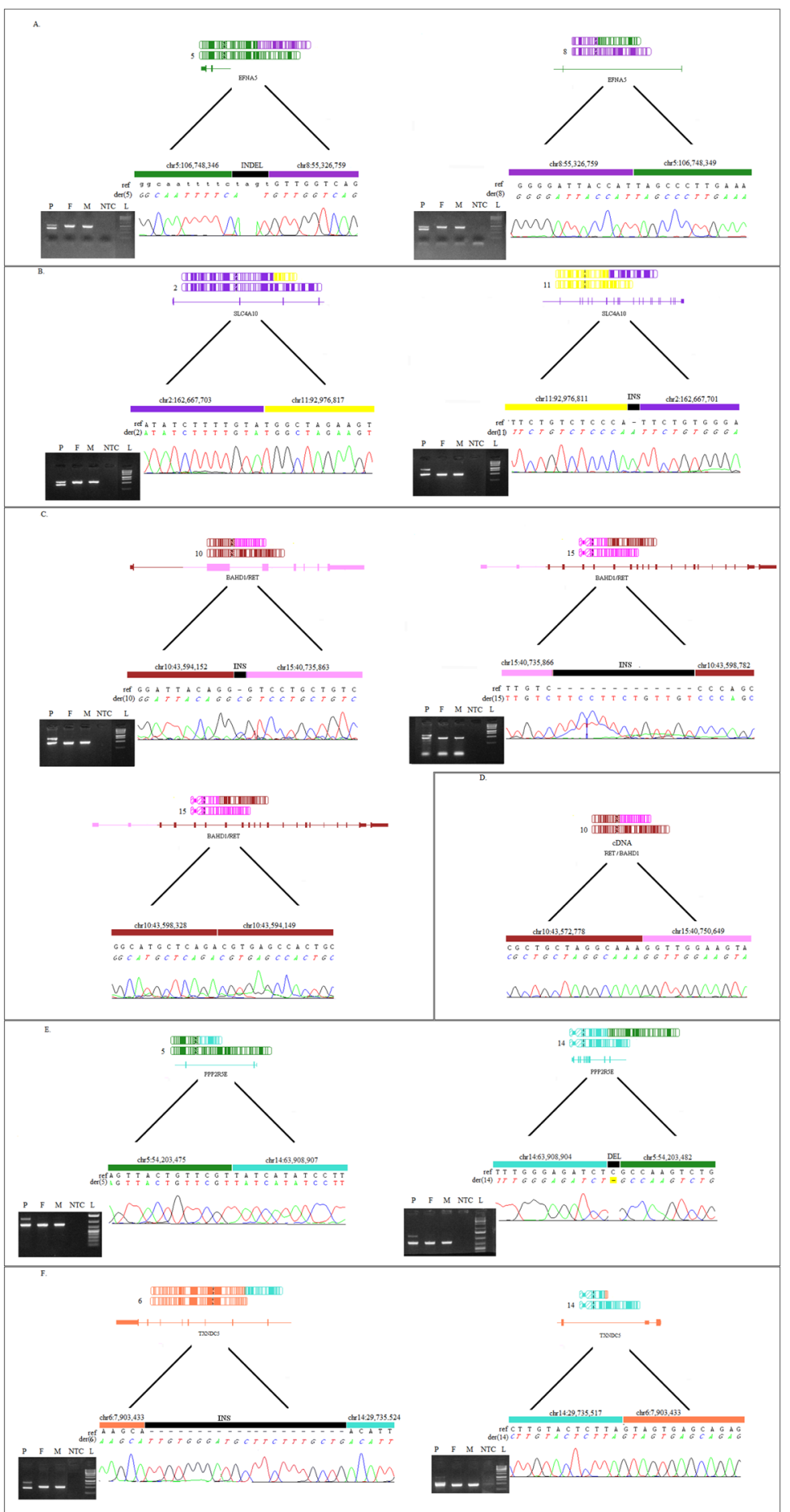

Figure 1 (A) Translocation between chromosomes 5 and 8 schematically shown with chromosome der 5 on the right and der8 on the left. On the right of both der 5 and der8 is Sanger sequencing validation of the breakpoint with the reference sequence. (B) Translocation between chromosomes 2 and 11 schematically shown with chromosome der 2 on the right and der11 on the left. On the right of both der2 and der11 is Sanger sequencing validation of the breakpoint with the reference sequence. (C) Translocation between chromosomes 10 and 15 schematically shown with chromosome der10 on the right and der 15 in the middle and on the left. On the right of both der10 and der15 is Sanger sequencing validation of the breakpoint with the reference sequence. The figure shows the $500 \mathrm{bp}$ insertion at chromosome 10 with the structure of the breakpoint between the insertion and chromosome 10 and the breakpoint and chromosome 15. (D) CDNA product composed of RET promoter and the whole coding part of BAHD1. (E) Translocation between chromosomes 5 and 14 schematically shown with chromosome der 5 on the left and der 14 on the right. On the right of both der 5 and der 14 is Sanger sequencing validation of the breakpoint with the reference sequence. (F) Translocation between chromosomes 6 and 14 schematically shown with chromosome der 6 on the left and der14 on the right. On the right of both der 6 and der 14 is Sanger sequencing validation of the breakpoint with the reference sequence. On the left of $A, B, C$ and $E$ are results of PCR screening using breakpoint specific primers. F, father; $L$, ladder; M, mother; NTC, nontemplate (negative) control; P, proband. 


\section{Proband 5}

SGMPS, based on 17 discordant reads and two split reads, defined the translocation as $46, \mathrm{XX}, \mathrm{t}(6 ; 14)(\mathrm{p} 25.1 ; \mathrm{q} 12)$ with exact location for chromosome der(6):

46,XX,t (6;14)(p25.1; 112)dn.seq[GRCh37/hg19]t (6;14) $(14$ qter $\rightarrow 14 q 12(29,735,524):: 6 \mathrm{p} 25.1 \quad(7,903,434) \rightarrow 6 q t e r)$; and for chromosome $\operatorname{der}(14) \quad 46, \mathrm{XX}, \mathrm{t}(6 ; 14)(\mathrm{p} 25.1 ; \mathrm{q} 12)$ dn.seq[GRCh37/hg19]tt $(6 ; 14)(14$ pter $\rightarrow 14$ q12(29,735,517) $:: 6 \mathrm{p} 25.1(7,903,433) \rightarrow 2$ pter $)$. The breakpoint in chr6 is located in the second intron out of nine introns of the TXNDC5 (MIM: 616412) gene, while the breakpoint in chr14 is located in non-coding DNA. In der(6) an insertion of $19 \mathrm{bp}$ is present at the breakpoint site (figure 1F). WES performed in the patient did not show the disease cause although we were not able to fully exclude the role of compound heterozygous mutations in MTCL1 (online supplementary table 2).

The four genes which were directly disrupted in probands with potentially novel diseases (ie, EFNA5, BAHD1, PPP2R5E, TXNDC5) had significantly higher $\mathrm{pLI}(\mathrm{p}<0.017)$ and DOMINO scores $(p<0.02)$ than the remaining genes.

\section{DISCUSSION}

In all nine probands, 11 disrupted genes were found, that is, EFNA5, EBF3 (MIM: 607407), LARGE (MIM: 603590), PPP2R5E, TXNDC5, ZNF423 (MIM: 604557), NIPBL (MIM: 608667), BAHD1, RET (MIM:164761), TRPS1 (MIM: 604386) and SLC4A10 (see online supplementary table 3 for further characteristics of these genes). Five subjects had translocations that disrupted genes with unknown (EFNA5, BAHD1, PPP2R5E, TXNDC5) or poorly delineated impact on the phenotype (SLC4A10) and these are discussed below. The remaining translocations are discussed in the online supplementary discussion.

In proband 1 we suggest that the disease is caused by the truncation of EFNA5. EFNA5 (ephrin-5) belongs to a group of ephrin ligands that splits into two groups, EFNA and EFNB, depending on the structure and the way of membrane attachment. ${ }^{23}$ EFNA5 may be intolerant to monoallelic loss-of-function $(\mathrm{LoF})$ mutations as suggested by $\mathrm{pLI}=0.89$ (observed LoF variants -0 , expected 7) and consistent with DOMINO score of 0.99 . Ephrin receptors are important for the development of the central nervous system and growth of various types of blood vessels. $^{2425}$ Seventeen per cent of homozygous Efna5 knockout mice had dorsal midline defects in the form of perinatally lethal anencephaly or haematoma in the dorsal midline of the cranium. ${ }^{26}$ The remaining knockout mice were apparently healthy but on close examination they harboured abnormalities of the lens and vitreous body of the eye. ${ }^{2627}$ The relevance of EFNA5 for proper eye development is further underscored by reports that proper closure of the optic fissure ${ }^{28}$ and retinal axon guidance ${ }^{29}$ both require EFNA5 signalling. ${ }^{30}$ Three rare (but not unique) EFNA5 variants were associated with age-related cataracts in a study of 140 Chinese patients. ${ }^{31}$ Thus, facial dysmorphy and vascular anomalies including persistent corneal fetal vascularisation and anomalies of heart and large vessels in our proband are broadly consistent with the known roles of ephrins/EFNA5 in encephalic/cranial pathology, vascular development and eye abnormalities.

In proband 2 the breakpoint in chromosome 2 was located in an intron of SLC4A10, while on chromosome 11 the breakpoint was found in non-coding DNA, thus suggesting that truncation of the SLC4A10 gene caused the condition. Additionally, WES was performed in the proband because SLC4A10 had features of a gene whose LoF should cause a recessive $(\mathrm{PRec}=0.997)$ rather than dominant disease $(\mathrm{pLI}=0.003, \mathrm{DOMINO}=0.205)$. However, no mutations affecting the other copy of SLC4A10 were found nor other variants which could explain the phenotype (online supplementary table 1). The SLC4A10 gene belongs to the SLC4 transporter family and encodes an $\mathrm{Na}+$ dependent transporter of $\mathrm{Cl}-\mathrm{HCO} 3$ - which likely affects the activity of neurons through a role in $\mathrm{pH}$ maintenance. ${ }^{32}$ In mice $\mathrm{Slc} 4 \mathrm{a} 10$ knockout reduced brain ventricle volume and protected against fatal epileptic seizures. ${ }^{32}$ Interestingly, in humans two cases of balanced translocations disrupting SLC4A10 were described: $\mathrm{t}(2 ; 13)(\mathrm{q} 24 ; \mathrm{q} 31)$ and $\mathrm{t}(1 ; 2)(\mathrm{q} 42 ; \mathrm{q} 31) .{ }^{14} 33$ In both cases, similar to our patient, developmental delay/mental retardation were found; in addition the first patient had epilepsy, while the second patient, in whom the HHAT (MIM: 605743) gene was additionally disrupted, had autism. ${ }^{143}$ In both described patients, similar to our proband, there was no evidence for mutation affecting the second SLC4A10 allele and the translocations breakpoint was located close to $5^{\prime}$ end of the gene (third, first and fourth introns, respectively). It is not clear why LoF of a single SLC4A10 allele should be pathogenic when caused by a translocation but tolerated when caused by point mutations. One explanation could be related to the non-coding transcripts which originate from 5' end of the SLC4A10 gene (ENST00000606386, ENST00000482861, ENST00000605990) whose expression could be deregulated by translocation. Another possibility is that the translocation disrupts chromatin structure influencing expression of neighbouring genes such as KCNH7 (MIM: 608169, pLI $=0.98$, DOMINO score $=0.91$ ) associated with bipolar spectrum disorder and schizophrenia ${ }^{34} 35$ and/or TBR1 (MIM: 604616, pLI=0.99, DOMINO score $=0.999$ ) —a gene located in the same TAD as the breakpoint and associated with intellectual disability and autism. ${ }^{36} 37$ In summary, we report the third patient with a translocation damaging the $5^{\prime}$ end of SLC4A10 providing additional evidence linking this locus with a dominant neurodevelopmental disease.

In proband 3 the breakpoints damaged RET and BAHD1, and formed a fusion gene including the $5^{\prime}$ part of RET and 3' part of BAHD1. Monoallelic RET mutations cause Hirschsprung disease (present in our proband) and hereditary cancer syndromes which may manifest in our proband later in life. As RET defects have not been linked with neurodevelopmental/psychiatric phenotypes, it is likely that these are caused by defect of BAHD1. BAHD1 is involved in epigenetic regulation through heterochromatin formation in interaction with HP1, MBD1 and HDAC5. ${ }^{38} 39$ Expression of BAHD1 is uniform in all tissues but is lowest in fetal brain. ${ }^{40}$ In our patient, the $5^{\prime}$ UTR from the BAHD1 gene is fused with the 19 exons of RET, while the whole coding part of $B A H D 1$ is fused with the proximal part of RET. We found the $R E T / B A H D 1$ fusion gene is expressed whereas we could not find the BAHD1/RET fusion product. Thus, in our proband BAHD1 may be overexpressed enhancing heterochromatin formation which may be pathogenic. ${ }^{39}$ Given the suggested role of BAHD1 in immune system ${ }^{41}$ it is also possible that recurrent infections in our proband are also part of the translocation phenotype.

In proband 4 we found a disruption of PPP $2 R 5 E$ encoding a regulatory subunit of the protein phosphatase $2 \mathrm{~A}$ expressed in the brain and heart. ${ }^{42-44}$ PPP2R5E might play a role in development of Alzheimer's disease (MIM: 104300) ${ }^{42}$ and its depletion leads to destabilisation of MTCL1, a protein responsible for the regulation of microtubule organisation, which may be pathogenic. $^{45}$ No LoF variants of PPP2R5E were found in ExAC (expected number -21); both pLI score (0.9994) and DOMINO score $(0.86)$ suggest that damage of a single copy of PPP $2 R 5 E$ may be pathogenic. 
In proband 5 the breakpoint was located in a conjoined gene BLOC1S5-TXNDC5 and was predicted to damage both the shRNA transcript and the TXNDC5 gene. Despite biologically important role of TXNDC5 for disulphide bond formation in proteins ${ }^{46}$ the gene is not expected to cause a dominant disease $(\mathrm{pLI}=0, \mathrm{DOMINO}=0.14)$. WES, together with family studies, showed the disease in proband 5 could potentially be caused by biallelic MTCL1 gene variants (MIM: 615766, online supplementary table 2). MTCL1 is involved in axon formation, ${ }^{47}$ however it has not been linked to human disease and the detected variants are predicted to be benign. Considering this, we speculate that the disease in proband 5 could be caused by LRPE. Interestingly, the TAD disrupted by the breakpoint in chr14 contains FOXG1 (MIM: 164874) whose monoallelic defects (including LoF variants) cause neurodevelopmental disorders with mental retardation, epilepsy and/or congenital Rett-like symptoms (MIM: 613454, online supplementary file 1). ${ }^{48}$

The finding that the four genes which were directly disrupted in probands with potentially novel diseases (ie, EFNA5, BAHD1, PPP2R5E, TXNDC5) had significantly higher pLI and DOMINO scores than the remaining genes indicates an enrichment in genes most likely to cause diseases with autosomal dominant inheritance. This, independently from other considerations, suggests that the defects of at least some of these genes do contribute to observed disease phenotypes.

In conclusion, we confirm the usefulness of SGMPS for analysis of BCTs and detection of novel candidate genes for dominant human disorders.

\section{Electronic database information}

OMIM: https://www.omim.org.

- ExAC: http://exac.broadinstitute.org.

- VarSome: https://varsome.com/.

- GTEXPORTAL: www.gtexportal.org.

\section{Author affiliations}

${ }^{1}$ Department of Medical Genetics, Medical University of Warsaw, Warsaw, Poland ${ }^{2}$ Postgraduate School of Molecular Medicine, Medical University of Warsaw, Warsaw, Poland

${ }^{3}$ Department of Medical Genetics, The Children's Memorial Health Institute, Warsaw, Poland

${ }^{4}$ Faculty of Mathematics, Informatics and Mechanics, Institute of Informatics, University of Warsaw, Warsaw, Poland

${ }^{5}$ Department of Pediatrics, Medical University of Warsaw, Warsaw, Poland ${ }^{6}$ genXone, Poznan, Poland

${ }^{7}$ Department of Clinical Genetics, Podlaskie Medical Center, Bialystok, Poland ${ }^{8}$ Department of Perinatology, Medical University of Bialystok, Bialystok, Poland ${ }^{9}$ Department of Forensic Medicine, Medical University of Warsaw, Warsaw, Poland ${ }^{10}$ Department of Medical Genetics, Institute of Mother and Child, Warsaw, Poland ${ }^{11}$ Department of Diagnostic Imaging, The Children's Memorial Health Institute, Warsaw, Poland

${ }^{12}$ Department of Pediatrics and Rare Disorder, Wroclaw Medical University, Wroclaw, Poland

Acknowledgements The authors are grateful to the patients and the parents for allowing this study to be published.

Contributors VMP, KS, RPo, RPI, MKW, RS, AG, JC, BP and AS wrote the manuscript. VMP, MK and MM performed the experiments. RPI, MR, AG, KC and MKW designed the experiment. VMP, MK and MM designed the pipeline. VMP, BP, AG and MS performed bioinformatic analysis. MM, MK, AS, RPo, PK, JC, EW, RS, KC and MKW contacted the patients. VMP, MR, AAK, AB, AW and JK performed next-generation sequencing. EJ preformed MRI analysis.

Funding The research was supported by the National Science Centre (NCN) grant number 2016/21/B/NZ5/02541.

Competing interests None declared.

Patient consent Parental/guardian consent obtained.
Ethics approval Ethics approval for the study was granted by the Ethical Committee at the Medical University of Warsaw (KB/127/2017).

Provenance and peer review Not commissioned; externally peer reviewed.

\section{REFERENCES}

1. Staff PO. PLOS ONE Staff. Correction: Accurate Breakpoint Mapping in Apparently Balanced Translocation Families with Discordant Phenotypes Using Whole Genome Mate-Pair Sequencing. PLoS One 2017;12:e0174190.

2. Warburton D. De novo balanced chromosome rearrangements and extra marker chromosomes identified at prenatal diagnosis: clinical significance and distribution of breakpoints. Am J Hum Genet 1991;49:995-1013.

3. Halgren C, Nielsen NM, Nazaryan-Petersen L, Silahtaroglu A, Collins RL, Lowther C, Kjaergaard S, Frisch M, Kirchhoff M, Brøndum-Nielsen K, Lind-Thomsen A, Mang Y, El-Schich Z, Boring CA, Mehrjouy MM, Jensen PKA, Fagerberg C, Krogh LN, Hansen J, Bryndorf T, Hansen C, Talkowski ME, Bak M, Tommerup N, Bache I. Risks and Recommendations in Prenatally Detected De Novo Balanced Chromosomal Rearrangements from Assessment of Long-Term Outcomes. Am J Hum Genet 2018;102:1090-103.

4. Harewood L, Chaignat E, Reymond A. Structural variation and its effect on expression. Methods Mol Biol 2012:838:173-86.

5. Mitelman F, Johansson B, Mertens F. The impact of translocations and gene fusions on cancer causation. Nat Rev Cancer 2007:7:233-45.

6. Mertens F, Johansson B, Fioretos T, Mitelman F. The emerging complexity of gene fusions in cancer. Nat Rev Cancer 2015:15:371-81.

7. Nothwang HG, Kim HG, Aoki J, Geisterfer M, Kübart S, Wegner RD, van Moers A, Ashworth LK, Haaf T, Bell J, Arai H, Tommerup N, Ropers HH, Wirth J. Functional hemizygosity of PAFAH1B3 due to a PAFAH1B3-CLK2 fusion gene in a female with mental retardation, ataxia and atrophy of the brain. Hum Mol Genet 2001:10:797-806.

8. Eykelenboom JE, Briggs GJ, Bradshaw NJ, Soares DC, Ogawa F, Christie S, Malavasi EL, Makedonopoulou P, Mackie S, Malloy MP, Wear MA, Blackburn EA, Bramham J, McIntosh AM, Blackwood DH, Muir WJ, Porteous DJ, Millar JK. A t $(1 ; 11)$ translocation linked to schizophrenia and affective disorders gives rise to aberrant chimeric DISC1 transcripts that encode structurally altered, deleterious mitochondrial proteins. Hum Mol Genet 2012:21:3374-86.

9. Lettice LA, Daniels S, Sweeney E, Venkataraman S, Devenney PS, Gautier P, Morrison $H$, Fantes J, Hill RE, FitzPatrick DR. Enhancer-adoption as a mechanism of human developmental disease. Hum Mutat 2011;32:1492-9.

10. Harewood L, Schütz F, Boyle S, Perry P, Delorenzi M, Bickmore WA, Reymond A. The effect of translocation-induced nuclear reorganization on gene expression. Genome Res 2010;20:554-64.

11. Harewood L, Fraser P. The impact of chromosomal rearrangements on regulation of gene expression. Hum Mol Genet 2014;23(R1):R76-R82.

12. Martin CL, Warburton D. Detection of Chromosomal Aberrations in Clinical Practice: From Karyotype to Genome Sequence. Annu Rev Genomics Hum Genet 2015;16:309-26.

13. Le Scouarnec S, Gribble SM. Characterising chromosome rearrangements: recent technical advances in molecular cytogenetics. Heredity 2012;108:75-85.

14. Nilsson D, Pettersson M, Gustavsson P, Förster A, Hofmeister W, Wincent J, Zachariadis V, Anderlid BM, Nordgren A, Mäkitie O, Wirta V, Käller M, Vezzi F, Lupski JR, Nordenskjöld M, Lundberg ES, Carvalho CMB, Lindstrand A. Whole-Genome Sequencing of Cytogenetically Balanced Chromosome Translocations Identifies Potentially Pathological Gene Disruptions and Highlights the Importance of Microhomology in the Mechanism of Formation. Hum Mutat 2017;38:180-92.

15. Langmead B, Salzberg SL. Fast gapped-read alignment with Bowtie 2. Nat Methods 2012;9:357-9.

16. Thorvaldsdottir H, Robinson JT, Mesirov JP, Viewer IG. IGV): high-performance genomics data visualization and exploration. Brief Bioinform 2013;14:178-92.

17. Ploski R, Pollak A, Muller S, Franaszczyk M, Michalak E, Kosinska J, Stawinski P, Spiewak M, Seggewiss H, Bilinska ZT. Does p. Q247X in TRIM63 cause human hypertrophic cardiomyopathy? Circ Res 2014;114:e2-5.

18. Ordulu Z, Wong KE, Currall BB, Ivanov AR, Pereira S, Althari S, Gusella JF, Talkowski $M E$, Morton CC. Describing sequencing results of structural chromosome rearrangements with a suggested next-generation cytogenetic nomenclature. Am J Hum Genet 2014;94:695-709.

19. Lek M, Karczewski KJ, Minikel EV, Samocha KE, Banks E, Fennell T, O'Donnell-Luria AH, Ware JS, Hill AJ, Cummings BB, Tukiainen T, Birnbaum DP, Kosmicki JA, Duncan LE, Estrada K, Zhao F, Zou J, Pierce-Hoffman E, Berghout J, Cooper DN, Deflaux N, DePristo M, Do R, Flannick J, Fromer M, Gauthier L, Goldstein J, Gupta N, Howrigan D, Kiezun A, Kurki MI, Moonshine AL, Natarajan P, Orozco L, Peloso GM, Poplin R, Rivas MA, Ruano-Rubio V, Rose SA, Ruderfer DM, Shakir K, Stenson PD, Stevens C, Thomas BP, Tiao G, Tusie-Luna MT, Weisburd B, Won HH, Yu D, Altshuler DM, Ardissino D, Boehnke M, Danesh J, Donnelly S, Elosua R, Florez JC, Gabriel SB, Getz G, Glatt SJ, Hultman CM, Kathiresan S, Laakso M, McCarroll S, McCarthy MI, McGovern D, McPherson R, Neale BM, Palotie A, Purcell SM, Saleheen D, Scharf JM, Sklar P, Sullivan PF, Tuomilehto J, Tsuang MT, Watkins HC, Wilson JG, Daly MJ, MacArthur DG. Exome 
Aggregation Consortium. Analysis of protein-coding genetic variation in 60,706 humans. Nature 2016:536:285-91.

20. Quinodoz M, Royer-Bertrand B, Cisarova K, Di Gioia SA, Superti-Furga A, Rivolta C. DOMINO: Using Machine Learning to Predict Genes Associated with Dominant Disorders. Am J Hum Genet 2017;101:623-9.

21. Crane E, Bian Q, McCord RP, Lajoie BR, Wheeler BS, Ralston EJ, Uzawa S, Dekker J Meyer $B J$. Condensin-driven remodelling of $X$ chromosome topology during dosage compensation. Nature 2015;523:240-4.

22. Rao SS, Huntley MH, Durand NC, Stamenova EK, Bochkov ID, Robinson JT, Sanborn AL, Machol I, Omer AD, Lander ES, Aiden EL. A 3D map of the human genome at kilobase resolution reveals principles of chromatin looping. Cell 2014; 159:1665-80.

23. Cheng C, Gong X. Diverse roles of Eph/ephrin signaling in the mouse lens. PLoS One 2011;6:e28147.

24. Pasquale EB. Eph receptor signalling casts a wide net on cell behaviour. Nat Rev Mol Cell Biol 2005;6:462-75.

25. Kuijper S, Turner CJ, Adams RH. Regulation of angiogenesis by Eph-ephrin interactions. Trends Cardiovasc Med 2007;17:145-51.

26. Cooper MA, Son Al, Komlos D, Sun Y, Kleiman NJ, Zhou R. Loss of ephrin-A5 function disrupts lens fiber cell packing and leads to cataract. Proc Natl Acad Sci U SA 2008; 105:16620-5.

27. Son Al, Sheleg M, Cooper MA, Sun Y, Kleiman NJ, Zhou R. Formation of persistent hyperplastic primary vitreous in ephrin-A5-/- mice. Invest Ophthalmol Vis Sci 2014:55:1594-606.

28. Noh H, Lee $H$, Park E, Park S. Proper closure of the optic fissure requires ephrin A5EphB2-JNK signaling. Development 2016;143:461-72.

29. Frisén J, Yates PA, McLaughlin T, Friedman GC, O'Leary DD, Barbacid M. Ephrin-A5 (AL-1/RAGS) is essential for proper retinal axon guidance and topographic mapping in the mammalian visual system. Neuron 1998;20:235-43.

30. Hara Y, Nomura T, Yoshizaki K, Frisén J, Osumi N. Impaired hippocampal neurogenesis and vascular formation in ephrin-A5-deficient mice. Stem Cells 2010;28:974-83.

31. Lin Q, Zhou N, Zhang N, Qi Y. Mutational screening of EFNA5 in Chinese age-related cataract patients. Ophthalmic Res 2014;52:124-9.

32. Jacobs S, Ruusuvuori E, Sipilä ST, Haapanen A, Damkier HH, Kurth I, Hentschke M, Schweizer M, Rudhard Y, Laatikainen LM, Tyynelä J, Praetorius J, Voipio J, Hübner CA. Mice with targeted Slc4a10 gene disruption have small brain ventricles and show reduced neuronal excitability. Proc Natl Acad Sci U S A 2008;105:311-6.

33. Gurnett CA, Veile R, Zempel J, Blackburn L, Lovett M, Bowcock A. Disruption of sodium bicarbonate transporter SLC4A10 in a patient with complex partial epilepsy and mental retardation. Arch Neurol 2008;65:550-3.

34. Genovese G, Fromer M, Stahl EA, Ruderfer DM, Chambert K, Landén M, Moran JL, Purcell SM, Sklar P, Sullivan PF, Hultman CM, McCarroll SA. Increased burden of ultra-rare protein-altering variants among 4,877 individuals with schizophrenia. Nat Neurosci 2016;19:1433-41.
35. Strauss KA, Markx S, Georgi B, Paul SM, Jinks RN, Hoshi T, McDonald A, First MB, Liu W, Benkert AR, Heaps AD, Tian Y, Chakravarti A, Bucan M, Puffenberger EG. A population-based study of KCNH7 p.Arg394His and bipolar spectrum disorder. Hum Mol Genet 2014:23:6395-406

36. McDermott JH, Study DDD, Clayton-Smith J, Briggs TA. The TBR1-related autistic-spectrum-disorder phenotype and its clinical spectrum. Eur J Med Genet 2018;61:253-6.

37. Hamdan FF, Srour M, Capo-Chichi JM, Daoud H, Nassif C, Patry L, Massicotte C, Ambalavanan A, Spiegelman D, Diallo O, Henrion E, Dionne-Laporte A, Fougerat A, Pshezhetsky AV, Venkateswaran S, Rouleau GA, Michaud JL. De novo mutations in moderate or severe intellectual disability. PLoS Genet 2014;10:e1004772.

38. Zhao D, Zhang $X$, Guan $H$, Xiong $X$, Shi $X$, Deng H, Li H. The BAH domain of BAHD1 is a histone H3K27me3 reader. Protein Cell 2016;7:222-6.

39. Bierne $H$, Tham TN, Batsche E, Dumay A, Leguillou M, Kernéis-Golsteyn $S$, Regnault B, Seeler JS, Muchardt C, Feunteun J, Cossart P. Human BAHD1 promotes heterochromatic gene silencing. Proc Nat/ Acad Sci U S A 2009;106:13826-31.

40. Nagase T, Ishikawa K, Suyama M, Kikuno R, Hirosawa M, Miyajima N, Tanaka A Kotani $\mathrm{H}$, Nomura N, Ohara 0 . Prediction of the coding sequences of unidentified human genes. XIII. The complete sequences of 100 new CDNA clones from brain which code for large proteins in vitro. DNA Res 1999;6:63-70.

41. Lebreton A, Lakisic G, Job V, Fritsch L, Tham TN, Camejo A, Matteï PJ, Regnault B, Nahori MA, Cabanes D, Gautreau A, Ait-Si-Ali S, Dessen A, Cossart P, Bierne H. A bacterial protein targets the BAHD1 chromatin complex to stimulate type III interferon response. Science 2011:331:1319-21.

42. Nematullah M, Hoda MN, Khan F. Protein Phosphatase 2A: a Double-Faced Phosphatase of Cellular System and Its Role in Neurodegenerative Disorders. Mol Neurobiol 2018;55

43. Eichhorn PJ, Creyghton MP, Bernards R. Protein phosphatase 2A regulatory subunits and cancer. Biochim Biophys Acta 2009;1795:1-15.

44. Benoist M, Gaillard S, Castets F. The striatin family: a new signaling platform in dendritic spines. J Physiol Paris 2006;99(2-3):146-53.

45. Hyodo $T$, Ito $S$, Asano-Inami $E$, Chen $D$, Senga T. A regulatory subunit of protein phosphatase 2A, PPP2R5E, regulates the abundance of microtubule crosslinking factor 1. Febs J 2016;283:3662-71

46. Horna-Terrón E, Pradilla-Dieste A, Sánchez-de-Diego C, Osada J. TXNDC5, a newly discovered disulfide isomerase with a key role in cell physiology and pathology. Int $J$ Mol Sci 2014:15:23501-18

47. Satake T, Yamashita K, Hayashi K, Miyatake S, Tamura-Nakano M, Doi H, Furuta Y, Shioi G, Miura E, Takeo YH, Yoshida K, Yahikozawa H, Matsumoto N, Yuzaki M, Suzuki A. MTCL1 plays an essential role in maintaining Purkinje neuron axon initial segment. Embo J 2017:36:1227-42

48. Ariani F, Hayek G, Rondinella D, Artuso R, Mencarelli MA, Spanhol-Rosseto A, Pollazzon M, Buoni S, Spiga O, Ricciardi S, Meloni I, Longo I, Mari F, Broccoli V, Zappella M, Renieri A. FOXG1 is responsible for the congenital variant of Rett syndrome. Am J Hum Genet 2008;83:89-93. 